\title{
EVALUATING SHORT STATURE AND HIGH YIELDING MAIZE HYBRIDS IN MULTIPLE ENVIRONMENTS USING GGE BIPLOT AND AMMI MODELS
}

\author{
Asgar AHMED ${ }^{I,}$, Akbar HOSSAIN ${ }^{1, *}$, Md. AMIRUZZAMAN ${ }^{2}$, Md. Ashraful ALAM ${ }^{3}$, Muhammad \\ FAROOQ ${ }^{4}{ }^{5}$, Ayman EL SABAGH ${ }^{6,7}$, Ferhat KIZILGECI ${ }^{8, *}$ \\ ${ }^{1}$ Bangladesh Wheat and Maize Research Institute, Dinajpur, BANGLADESH. \\ ${ }^{2}$ Plant Breeding Division, Bangladesh Agricultural Research Institute, Gazipur, BANGLADESH. \\ ${ }^{3}$ Spices Research Centre, Bangladesh Agricultural Research Institute, Bogra, BANGLADESH. \\ ${ }^{4}$ Sultan Qaboos University, College of Agricultural and Marine Sciences, Department of Crop Sciences, \\ Al-Khoudh-123, OMAN. \\ ${ }^{5}$ Agricultural of University, Department of Agronomy, Faisalabad, Punjab, PAKISTAN. \\ ${ }^{6}$ Kafrelsheikh University, Faculty of Agriculture, Department of Agronomy, EGYPT. \\ ${ }^{7}$ Siirt University, Faculty of Agriculture, Department of Field Crops, Siirt, TURKEY. \\ ${ }^{8}$ Mardin Artuklu University, Kiziltepe Vocational School, Department of Plant and Animal Production, \\ Mardin, TURKEY. \\ *Corresponding authors: tanjimar2003@yahoo.com (Akbar Hossain); ferhat_kizilgeci@hotmail.com \\ (Ferhat Kizilgeci)
}

Received: 09.06.2019

\begin{abstract}
In Bangladesh, maize stands second place after rice; since it faces diverse natural calamities during its highest growing season (rabi/winter), particularly strong storm during the reproductive stage. Sometimes in some regions, this crop is completely damaged by natural disasters. Considering the burning issue, thirteen hybrids, including 10 previously selected short stature hybrids were evaluated against three local and standard checks: 'BHM-9', '981' and 'Sunshine' in two consecutive years in seven locations of Bangladesh. Combined analysis over locations and seasons instigated that genotypes 'Sunshine', '981' and 'G10' were the top-high yielders, while genotypes 'G1', 'G2', 'BHM-9' and 'Sunshine' were found the most stable. On the other hand, five genotypes such as 'G3', 'G4', 'G6', 'G8' and 'G9' had the below-average mean yield and the genotypes 'G6' and 'G9' were the most unstable. Among the seven environments, Jamalpur, Joydebpur and Dinajpur were most discriminating and Ishwardi was the least discriminating; whereas Joydebpur was more representative and Borishal was the least representative of other test environments. In the case of plant and ear height, most of the genotypes showed a lower value than all the checks, which was desirable. But among the top three high yielders, local cross-genotype, the 'G10' had the lowest and more stable value for both plant height and ear height. Therefore, considering the plant and ear height, grain yield, and yield stability, the genotype 'G10' has been recommended for release as commercial variety and has been released as new maize variety in Bangladesh with the local name of 'BARI Hybrid Maize-16' (BHM-16).
\end{abstract}

Keywords: AMMI model, GGE biplot, local crosses and check, maize, multiple environments,

\section{INTRODUCTION}

Maize (Zea mays L.) is one of the most important cereals in the world (Shiri et al., 2010) grown on more than 180 million hectares area with 1,170 million metric tons of grain production. Maize is a $\mathrm{C}_{4}$ plant and has wider adaptability to grow in diverse environmental conditions (Gerpacio and Pingali, 2007). The area under maize is increasing rapidly in Asian countries. For instance, in South Asia, maize is grown in an area of 14 Mha with an average of $3.8 \mathrm{t} \mathrm{ha}^{-1}$ (FAOSTAT, 2018). Despite several limitations in South-Asia, such as frequent climatic extremes, including heat, drought and/or waterlogging, pre-and post-harvest pathogens and insectpests, weeds, and lack of access to quality seed in some areas, some of the Asian countries have attained a remarkable achievement in terms of area, production and productivity. The remarkable growth rate of maize in the South-Asia including Bangladesh is due to good market price as a result of the rapid expansion of the poultry industry, wider adaptability of maize in non-traditional areas, also a resilient role of the hybrid seed production by the private sector, and the development and delivery of higher-yielding, single-cross hybrids (Ali et al., 2010; Timsina et al., 2010; Timsina et al., 2018). Shiferaw et al. (2011) found that about $70 \%$ of total maize production is 
used by animal feed industries and ever-increasing population growth of this area will trigger the demand of meat and eggs as a protein source which ultimately fueled the production of maize. Maize is also used as sweeteners and food additives in the food industry which is another crucial end-user segment of maize (Gulati et al., 2008). Due to climate change, maize grain yield (GY) potentiality has been disrupted in Bangladesh. Changing climate is a global issue which increases the frequency and severity of disasters that disrupts production cycles, livelihoods and trade flow that affects food security through value chains (Rahman et al., 2017). Between 2005 and 2014, natural hazards in agriculture sector account for about $23 \%$ of the total damage and losses in developing countries which costs about $\$ 93$ billion, where extreme temperatures, storms and wildfires, set the sector back over $\$ 21.5$ billion which is about $23 \%$. The scenario of overall losses in Asia is comparatively higher, peaking in 2013 (FAO, 2017). As one of the most climate-vulnerable countries of the world, Bangladesh frequently faces severe storms with thunderstorms (formed by hot and humid air during ongoing pre-monsoon period have become more deadly than other major storms), occurs from late February to early June, peaking in April and generally accompanying with strong winds, heavy torrential rain, cyclones and hail. In 2018, the Bangladesh Meteorological Department (BMD) recorded 3-4 severe and 7-8 mildkalbaishakhi (storm) in April (Daily Sun, 2018). Generally, it happens all over the season uniformly with an average of over 150 times happening in a year (Mayumi Ozaki, 2016). But its distribution has been changed in the last five years and it occurs mainly in the mid-February to mid-March which is the grain filling stage of maize.The varieties which are generally tall or have higher ear position might be damaged totally. So as disaster risk reduction (DRR) strategy, the first and foremost goal is to develop a high yielding short stature single cross hybrid that would not let our country push back and our communities into poverty loops during the frequent hazardous event (storm) (FAO, 2017). The main constraint of this development is the yield which is a complex character dependent on several other characters and is highly influenced by many genetic factors as well as environmental fluctuations. It is positively correlated with plant height; however, the selection is often incompetent due to genotype by environment interactions (GE)i.e., when genotypes fail to have the same relative performance in different environments (Gauch, 2006).Several statistical methods (including singlevariable, multivariate and non-parametric methods) have been successfully used by earlier studies (Lin et al., 1986; Karimizadeh et al., 2006) to find out the adaptive and stable genotypes under diverse environments. Among them the GGE biplot analysis i.e., the genotype main effect $(G)$ and the genotype $\times$ environment interaction $(\mathrm{G} \times \mathrm{E})$ (Hossain et al., 2018; Kizilgeci et al., 2019) is a useful tool for plant breeders and geneticists to find out the maximum yield and stable genotypes across multiple locations as well as to find out the best favourable location for a specific genotype through acquiring a graphical form (Gabriel, 1971; Yan and Kang, 2003; Koutis et al., 2012). The GGE biplot was constructed from the first two principal components ( $\mathrm{PC} 1$ and $\mathrm{PC} 2$ ) that were derived by subjecting environment-center GY means to singularvalue decomposition. Similar to GGE biplot method, the AMMI (The Additive Main effects and Multiplicative Interaction) model is also an effective method to find out the genotype(s) which are stable and suitable to cultivate in a specific or multiple environments (Zobel et al., 1988; Duarte and Vencovsky, 1999). Therefore, the present study was undertaken to evaluate the short stature single cross maize hybrids suitable for multiple environments based on yield stability, adaptability and environmental stratification by using the methods such as Francis and Kannenberg's coefficient of variation, Eberhart and Russel's coefficients, AMMI and GGE biplot by using the test data.

\section{MATERIALS AND METHODS}

Location of the research

This experiment was conducted at seven different locations (viz., Joydebpur, Jamalpur, Rangpur, Dinajpur, Borishal, Ishwardi and Jessore) during two consecutive years (2016-17, 2017-18). The first year in five locations viz., at the Gazipur, Rangpur, Jamalpur, Borishal, and Jessore during rabi season of the 2016-17 and second year in six locations viz., Gazipur, Rangpur, Borishal, Jessore, Pabna and Dinajpur during rabi season of 2017-18.

\section{Experimental treatments and design}

Treatments were thirteen hybrids, including 10 previously selected short stature genotypes (developed through the local cross) were evaluated against three local and standard checks: BARI Hybrid Maize-9 ('BHM-9') (BARI released latest hybrid variety), '981' (marketing in Bangladesh by Monsanto) and 'Sunshine' (marketing in Bangladesh by Syngenta). All genotypes were evaluated in consecutive 2 years (2016-17 \&2017-18). While, the first year in five locations viz., at the Gazipur, Rangpur, Jamalpur, Borishal, and Jessore during rabi season of the 2016-17 and the second year in six locations viz., Gazipur, Rangpur, Borishal, Jessore, Pabna and Dinajpur during rabi season of 2017-18. Treatments were arranged in a randomized complete block design with three replications. Seven locally developed (through recycle) inbred lines were used to produce those single cross hybrids; BML (BARI Maize Line) 59 and BML-58 were used as female parent whereas other five inbred lines were used as male parents in all possible combinations without reciprocals (Table 1). 
Table 1. Mean performance of maize hybrids evaluated for two consecutive years across seven different environments

\begin{tabular}{|c|c|c|c|c|c|c|c|}
\hline Entry & Crosses/varieties & & $\begin{array}{c}\text { DPS } \\
\text { (days) }\end{array}$ & $\begin{array}{c}\text { DS } \\
\text { (days) }\end{array}$ & $\begin{array}{c}\text { Plant height } \\
(\mathrm{cm})\end{array}$ & $\begin{array}{c}\begin{array}{c}\text { Ear height } \\
(\mathrm{cm})\end{array} \\
\end{array}$ & $\begin{array}{c}\text { Grain yield } \\
\left(\mathrm{t} \mathrm{ha}^{-1}\right)\end{array}$ \\
\hline G1 & BML-48× BML-62 & \multirow{10}{*}{$\begin{array}{l}\tilde{U} \\
0 \\
0 \\
0 \\
0 \\
\tilde{0} \\
\tilde{0} \\
\tilde{0}\end{array}$} & 82 & 84 & 179 & 72 & 10.70 \\
\hline G2 & BML-48× BML-63 & & 81 & 84 & 186 & 71 & 10.89 \\
\hline G3 & BML-48× BML-67 & & 82 & 84 & 186 & 72 & 10.26 \\
\hline G4 & BML-48× BML-70 & & 83 & 85 & 172 & 72 & 8.90 \\
\hline G5 & BML-48× BML-71 & & 83 & 86 & 179 & 73 & 10.98 \\
\hline G6 & BML-59 × BML-62 & & 83 & 87 & 174 & 67 & 8.47 \\
\hline G7 & BML-59 × BML-63 & & 83 & 86 & 187 & 81 & 10.89 \\
\hline G8 & BML-59 × BML-67 & & 84 & 86 & 193 & 82 & 10.30 \\
\hline G9 & BML-59 $\times$ BML-70 & & 81 & 83 & 174 & 73 & 9.66 \\
\hline G10 & BML-59 × BML-71 & & 84 & 86 & 188 & 83 & 11.74 \\
\hline G11 & BHM-9 & \multirow{4}{*}{ 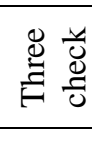 } & 86 & 88 & 234 & 121 & 11.21 \\
\hline G12 & 981 & & 84 & 87 & 225 & 98 & 11.95 \\
\hline \multirow[t]{2}{*}{ G13 } & Sunshine & & 83 & 86 & 223 & 98 & 11.99 \\
\hline & Mean & & 83 & 86 & 192 & 82 & 10.61 \\
\hline
\end{tabular}

*DPS, days to pollen shedding; DS, days to silking; BHM-9, BARI high yielding of maize hybrid 9; 981, from Monsanto; Sunshine, from Syngenta

\section{Experimental procedure}

Seeds of each entry were sown in 2 rows, $4 \mathrm{~m}$ long plot with $60 \mathrm{~cm} \times 25 \mathrm{~cm}$ spacing. During the first year $(2016)$, seeds of all genotypes/varieties were sown on 27 November, 28 November, 1 December, 1 December and 4 December at the location of Gazipur, Rangpur, Jamalpur, Borishal and Jessore respectively; while in the second year (2017), seeds were sown on 27 November, 14 November, 30 November, 17 November, 19 November and 18 November at the location of Gazipur, Jessore, Barisal, Rangpur, Pabna and Dinajpur respectively. One vigorous seedling per hill was kept after thinning. Fertilizers were applied at the rate of 220-180-50-120-10$4 \mathrm{~kg} \mathrm{ha}^{-1}$ of N (as urea), $\mathrm{P}$ (as triple superphosphate), $\mathrm{K}$ (as muriate of potash), $\mathrm{S}$ (as gypsum), $\mathrm{Zn}$ (as zinc sulphate) and B (as boric acid) respectively. All P, K, S, B and Zn and one-third urea were applied at the time of final land preparation. Fertilizer $\mathrm{N}$ was applied in at two equal splits: $1 / 3$ at 24 days after sowing (DAS) and 1/3 at 54 DAS. Two irrigations were applied during the growing season of each year; first was applied 24 DAS; while the second was applied 54 DAS. No insecticide and fungicide were applied, but weeds were controlled manually at 30 DAS.

\section{Data collection}

Data on days to pollen shading, days to silking, plant height, ear height and grain yield (GY) were recorded in both years. For yield data, 10 middle rows were harvested at full maturity from each plot to avoid border effects. Then harvested samples were bundled and tagged separately and dried, then manually threshed separately on a threshing floor. Data on GY was adjusted at $15 \%$ moisture.

\section{GGE Biplot and AMMI Model}

\section{GGE biplot analysis}

The GGE biplot analysis (i.e., the genotype main effect $(G)$ and the genotype $\times$ environment interaction $(\mathrm{G} \times \mathrm{E})$ (Hossain et al., 2018; Kizilgeci et al., 2019) is a useful tool for plant breeders and geneticists to find out the maximum yield and stable genotypes across multiple locations; as well as to find out the best favourable location for a specific genotype through acquiring a graphical form (Gabriel, 1971; Yan and Kang, 2003; Koutis et al., 2012). The GGE biplot was constructed from the first two principal components (PC1 and PC2) that were derived by subjecting environment-center GY means to singular-value decomposition. The options used for data analysis were no transformation (Transform $=0$ ), no standardization (Scale $=0$ ), and environment centering (Centering $=2$ ). The biplot was based on environmentfocused singular-value partitioning $(\mathrm{SVP}=2)$ and was therefore appropriate for visualizing the relationships among locations. When relationships among genotypes were desired, the biplot was based on genotype focused singular-value partitioning $(\mathrm{SVP}=1)$. The following GGE biplot model was used (Yan and Kang, 2003):

$$
Y_{i j}-\bar{Y}_{j}=\lambda_{1} \xi_{i 1} \eta_{j 1}+\lambda_{2} \xi_{i 2} \eta_{j 2}+\varepsilon_{i j}
$$

where $Y_{i j}$ is the mean yield of genotype ' $i$ ' in environment ' ${ }_{j}$ '; ' $\bar{Y}_{j}$ ' is the mean yield across all genotypes in the environment ' $j$ '; $\lambda_{1}$ and $\lambda_{2}$ are the singular values for $\mathrm{PC} 1$ and $\mathrm{PC} 2$, respectively; ' $\zeta_{i 1}$ ' and ' ' ${ }_{i 2}$ ' are the PC1 and PC2 scores, respectively, for genotype ' ${ }_{i}$ '; $\eta_{j 1}$ and $\eta_{j 2}$ are the $\mathrm{PC} 1$ and $\mathrm{PC} 2$ scores, respectively, for environment ' $j$ '; and ' $\varepsilon_{i j}$ ' is the residual of the model associated with genotype ' $i$ ' in environment ' $j$ '.

\section{AMMI Model}

Duarte and Vencovsky (1999) first proposed the AMMI (The Additive Main effects and Multiplicative Interaction) analyses. The AMMI model is the most effective method to find out the genotype(s) which are stable and suitable to cultivate in specific or multiple environments (Zobel et al., 1988). Thus, the mean response of the genotype $\mathrm{i}$ in environment $\mathrm{j}\left(Y_{i j}\right)$ is modelled by: 


$$
Y i j=\mu+\mathrm{gi}+\mathrm{aj}+\sum \lambda \mathrm{k} \gamma \mathrm{ik \alpha j \textrm {k }}+\rho \mathrm{ij}+\mathrm{eij} .
$$

According to Eberhart and Russel (1966), regression coefficient (bi), deviation from regression $\left(\mathrm{S}^{2} \mathrm{di}\right)$ and the stability parameters were also estimated through the AMMI model. Significance of differences among bi value and unity was tested by t-test, between $\mathrm{S}^{2} \mathrm{di}$ and zero by Ftest.

\section{Statistical Analysis}

Before the GGE biplot and the AMMI model analysis, data on grain yield for all genotypes across locations were examined by $\mathrm{R}$ package (version 2.15.3) at the $5 \%$ level of significance (R Core Team, 2013).

\section{RESULTS AND DISCUSSION}

Phenology and growth of thirteen maize genotypes across the location

Performance of all the crosses along with three checks i.e., 'BHM 9', '981' and 'Sunshine' are presented in Table 1. All the crosses and varieties exhibited statistically similar days to pollen shading (DPS) and days to silking (DS) but they differ significantly by plant height, ear height and grain yield. Cross No. 10 showed at per yield with the top two highest yielders ('Sunshine' and '981'). Moreover, all the crosses (G1 to G10) had significantly short stature and lower ear height or ear position (plant height/ear height) than the other two varieties (Table 1). All genotypes had the tallest plant at Jamalpur region and the shortest plants were found in Rangpur, except three checks. All the 10 genotypes had the shorter plant height in all environments than the checks. Among them, genotype 'G4' gave the shortest plant in all seven locations, while genotype ' 11 ' gave the tallest plant (Fig. 1A). Regarding the ear length, all genotypes had the maximum ear length at Jamalpur, while Rangpur had the shortest for all genotypes, except genotype 'G3', and three checks (i.e., 'G11', 'G12' \& 'G13'). While, genotype 'G6' had the shortest ear in all locations, while genotype ' $\mathrm{G} 11$ ' had the maximum ear length. All the 10 genotypes had the shorter ear length in all environments than the checks (Fig. 1B). The combined analysis of variance for grain yield showed highly significant differences for locations (environment), genotypes and $\mathrm{G} \times \mathrm{E}$ interaction (Table 2). As the crosses and check genotypes/varieties performed differentially in different environments, the selection of superior hybrid(s) would be more effective if it is done considering mean GY and Yield stability simultaneously rather than average GY alone (Shiri, 2013). Significant environment and $G \times E$ interaction sum of squares instigate diverse environment and hybrids' differential responses across environments. Additionally, decomposition of GEI through AMMI analysis identified two significant principal components explaining $64.54 \%$ of total variance interaction (43.62\% IPCA1 and $20.92 \%$ IPCA2). The main drawback of the combined analysis of variance is that it can only identify whether $G \times E$ interaction is significant or not, and it cannot justify whether the GY is stable or not. Therefore, suitable statistical methods are needed to evaluate and identify stable hybrid(s). To examine the environmental distinction and interpret $\mathrm{G} \times \mathrm{E}$ interface, the GGE biplot method was employed from which information about genotype main effects and $G \times E$ interaction could be dug out at the same time. It can judge genotypic stability and combinations of genotypic yield stability and grain yield in different environmental conditions. One of the most important applications of the GGE biplot analysis in plant breeding programs is determination and grouping of target environments. In this analysis, environments were evaluated and grouped with the same genotype reaction.
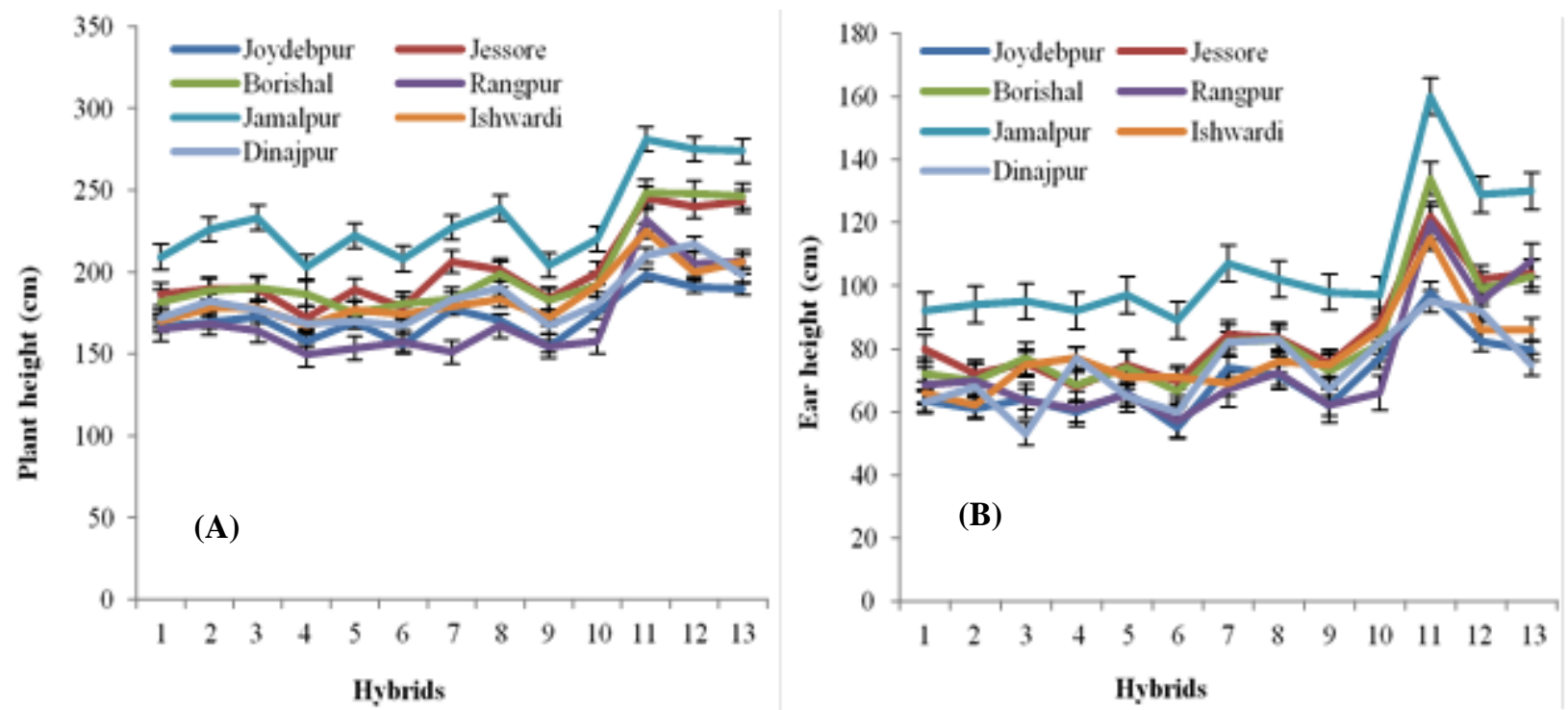

Figure 1. (A) Plant height (two years pooled) of thirteen maize hybrids across the locations. (B) Ear height (two years pooled) of thirteen maize genotypes/varieties across the location in both year. In both figures, SE $( \pm)$ was calculated for each hybrid in three replications. 
Table 2. AMMI analysis of variance for grain yield $\left(\mathrm{t} \mathrm{ha}^{-1}\right)$ of 13 maize genotypes across 7 different environments

\begin{tabular}{lllll}
\hline Source of Variation & DF & SS & MS & Explained SS (\%) \\
\hline Environments (E) & 6 & 100.09 & $16.68^{* *}$ & 15.11 \\
Genotypes (G) & 12 & 468.98 & $39.08^{* *}$ & 70.84 \\
G $\times$ E Interaction (GEI) & 72 & 92.94 & $1.29 * *$ & 14.04 \\
IPCA1 & 17 & 27.64 & $1.62^{* *}$ & 43.62 \\
IPCA2 & 15 & 13.25 & $0.88^{*}$ & 20.92 \\
IPCA3 & 13 & 10.59 & 0.81 & 16.71 \\
IPCA4 & 11 & 6.32 & 0.57 & 9.97 \\
IPCA5 & 9 & 3.08 & 0.34 & 4.86 \\
IPCA6 & 7 & 2.46 & 0.35 & 3.89 \\
IPCA7 & 5 & 0 & 0 & 0 \\
Error & 338 & 178.77 & 0.52 & 0 \\
\hline
\end{tabular}

\section{Which won where}

The GEI pattern can be identified effectively through GGE biplot polygon display where data acquired from the multivariate models of genotypes/varieties/hybrids and environments are plotted concurrently in one figure (Yan et al., 2001). Environment-centred means were subjected to singular value decomposition (SVD), which yielded principal components and then the first principal component (Axis1) scores were plotted against their respective scores for the second principal component (Axis2) to construct GGE biplot (Mohammadi et al., 2010; Hossain et al., 2018). Here, two years average yields of thirteen crosses and varieties over seven environments were used to perform GGE biplot method. The principal component Axis1 elucidated $83.63 \%$ genotype main effects, while second principal component Axis2 illustrated $7.51 \% \mathrm{G} \times \mathrm{E}$ interaction and thus the GGE biplot explained $91.14 \%$ of the total variation of GY (Fig. 2A). By connecting different points of genotype, located far away from the centre, a polygon has been drawn in Fig. 3, so that all the remaining genotypes would be in the polygon and from which different interpretations regarding GxE interaction effect can be drawn. It is evidently displayed that which genotype won in which environments, thus assisting mega-environment documentation (Yan et al., 2000; Dimitrios et al., 2008). Other researchers (Sabaghnia et al., 2008; Choukan, 2011; Shiri, 2013) have also deal with this method. In the Fig. 2A, genotypes 'G4', 'G6', 'G9', 'G10', 'G12' and 'G13' are found at the peak of the polygonal view of GGE biplot display and thus instigate the strongest or weakest genotypes regarding GY in one, several or all environments. Genotypes 'G10', 'G12' and 'G13'were considered as the superior hybrids as they had the highest yield in all the test locations (environments). Crosses (hybrids) 'G1', 'G2', 'G5', 'G7' and 'G11' were not significantly different from those hybrids. Although hybrids 'G4', 'G9' and 'G6'positioned at the apex of the GGE biplot polygon view, but they had low GY in all the evaluated environments.
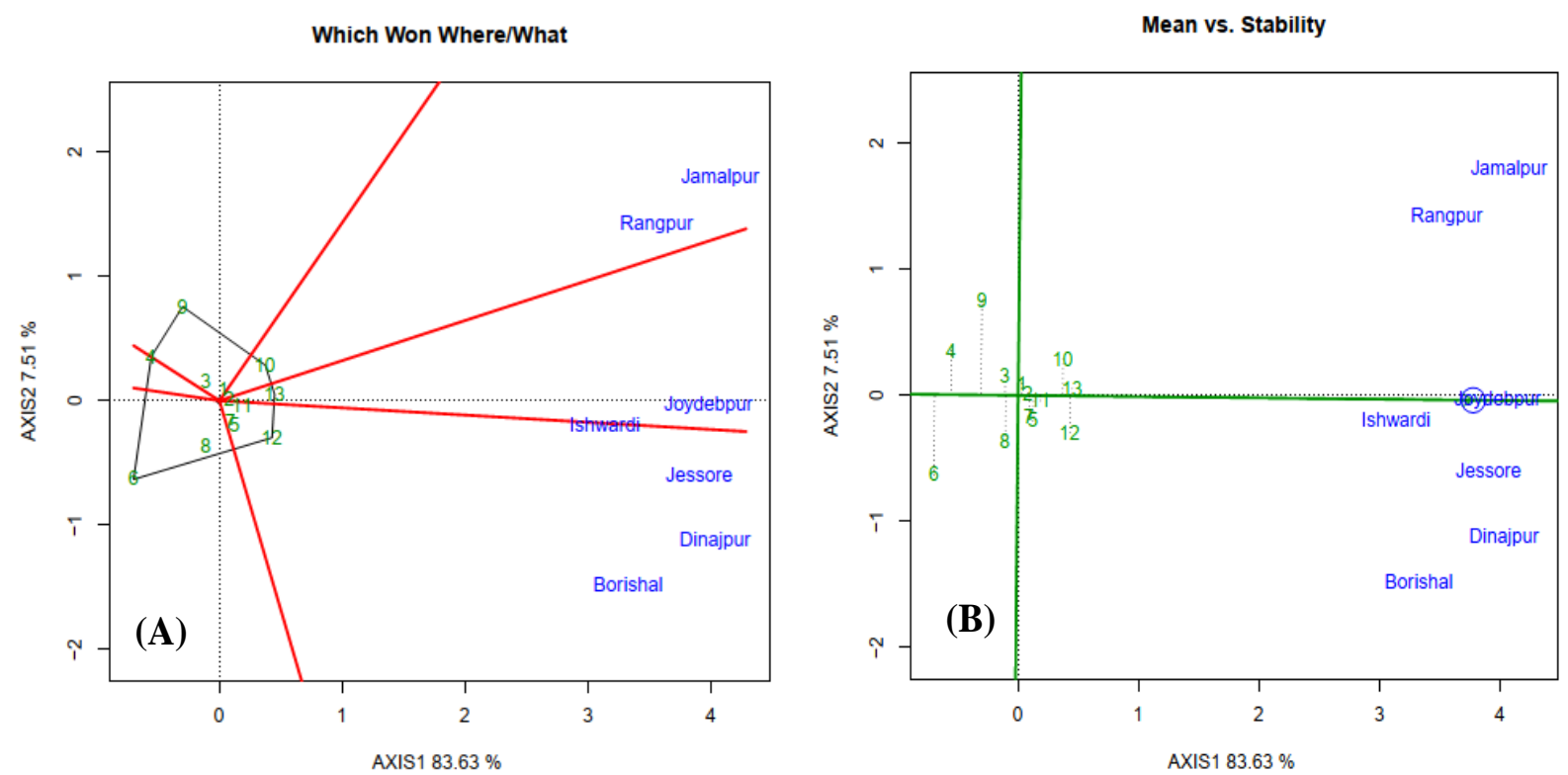

Figure 2. (A) Polygon view of GGE biplot analysis (based on grain yield) for grouping environments according to their suitability as for specific genotype or for all genotypes. (B) Evaluation of thirteen maize genotypes based on both grain yield \& their yield stability across the seven locations. 

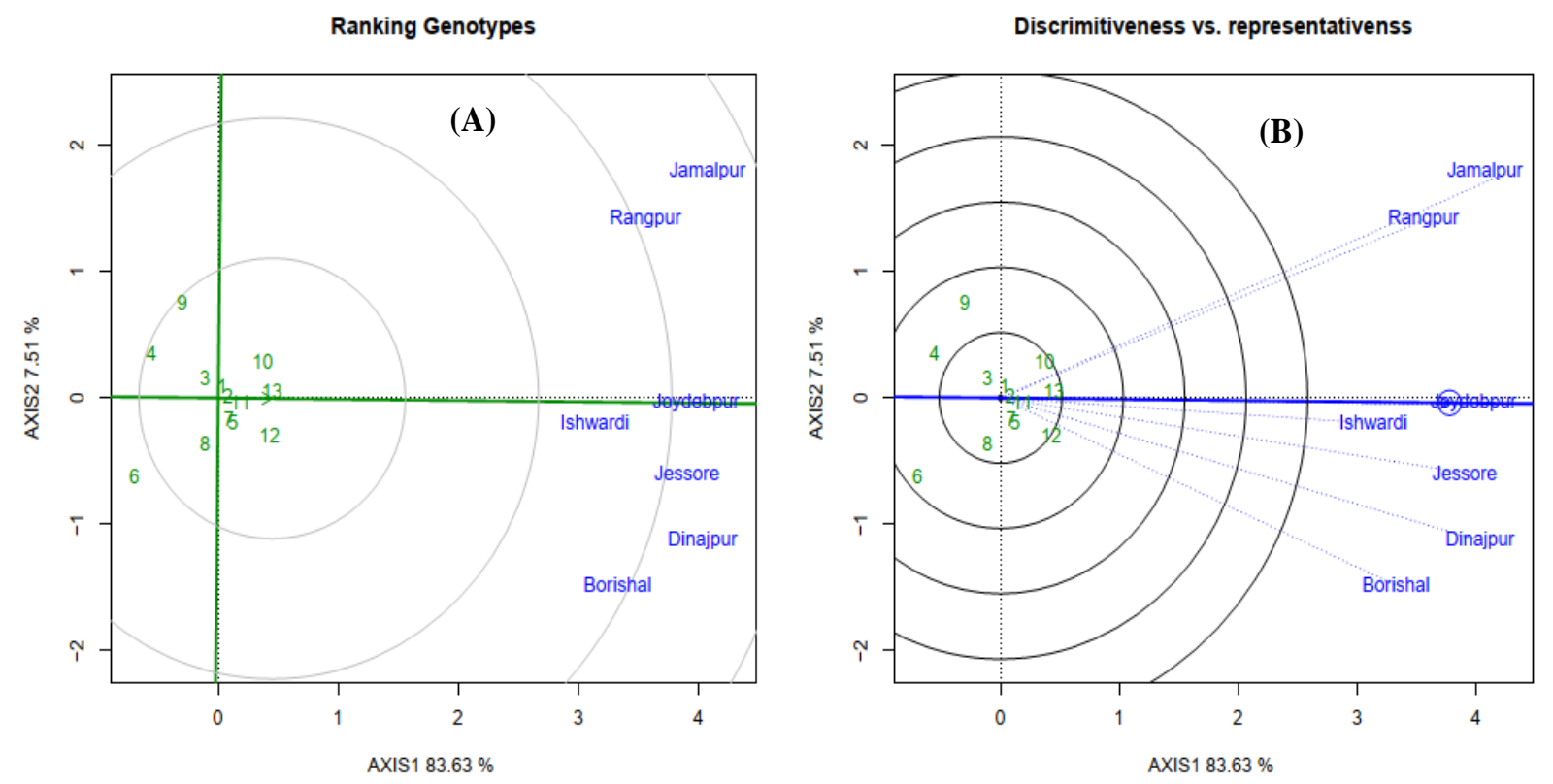

Figure 3. (A) Polygon view of GGE biplot analysis for ranking the genotypes as compared with the high yield potential and stable genotype. (B) Polygon display of GGE biplot for rank the environments/locations as compared with the ideal environment/location based on grain yieldand yield stability of all genotypes as well as locations specific genotypes.

\section{Average Tester coordination for entry evaluation / Mean vs. Stability}

Yield stability and GY potentiality of all maize genotypes were evaluated by using average environment coordination (AEC) of GGE biplot polygon view (Yan et al., 2001; Yan and Hunt, 2002). An AEC is fixed up by average Axis1 and Axis 2 scores of all locations which are pointed out by a circle. A line which is linked between the biplot origin and AEC is called the average environment axis, where average GY generally higher for the best performing genotypes. Another perpendicular line to the AEC also passes through the centre illustrates the Yield stability of all genotypes and genotypes on this axis in either direction represents $\mathrm{G} \times \mathrm{E}$ interaction and yield stability (Yan and Hunt, 2002). The greater distance indicates the greater $\mathrm{G} \times \mathrm{E}$ interaction and lower yield stability. Depending upon mean GY values an average tester direction curve (Fig. 2B) was drawn to estimate GY performance and yield stability. In Fig. 2B, genotypes 'G1' and 'G2' had high yield stability and average GY; whereas genotype 'G10' had average yield stability,but high GY. But the genotype 'G13' had both high GY and yield stability. However, genotypes 'G5', 'G7' and 'G11' had both average GY and stability, while genotype 'G3' had low GY and high stability. Low stability and high GY were observed in genotype 'G12', while low GY together with very low stability was observed in genotype 'G6' and 'G8'. Meanwhile, genotypes 'G4' and 'G9' had average stability and low GY. To sum up we can say that genotypes 'G10' and 'G13'were the superior genotypes with satisfactoryyield stability and high GY.

\section{Ranking genotypes}

In this GGE biplot method test genotypes are compared to an 'ideal' genotype which is hypothetically determined based on maximum GY with higher yield stability i.e., it will express no $\mathrm{G} \times \mathrm{E}$ interaction. This genotype is determined by the maximum length on the average vector of the high yield potential genotypes and plays the lowest $\mathrm{G} \times \mathrm{E}$ interaction. In Fig. 3A, concentric circles have been drawn centring the hypothetical genotype to govern the distance between all evaluating genotypes and the best/ideal genotype graphically. A genotype nearest to the centre is well-thought-out the best genotype with average high GY and good yield stability. In Fig. 3A, the genotype 'G13' is located at the circles and is confirmed as an ideal genotype with higher GY and better yield stability. Whereas, genotypes 'G10', 'G11' and 'G12' were close to the superior genotype 'G13', also identified as better hybrids. However, the genotype 'G6'could not be considered as a higher GY and yield stable genotype, as it was far away from genotype 'G13'.

\section{Discrimination vs. representation}

To group different environments according to their similarities and to identify stable genotypes, the GGE biplot method can also be used successfully. Relationships among different environments could be justified by correlation coefficients and environments with strong positive correlation could be classified into the same group and thus experiments could be conducted in one environment of a group which would represent the others (Yan and Kang, 2003). In the biplot graph, correlation intensity is calculated by the cosine of the angle between environment vectors. In the case of null correlation, the 
angle of cosine would be $90^{\circ}$ and a strong correlation would be represented by cosine $0^{\circ}$, while cosine $180^{\circ}$ stands for a strong negative correlation. The directions/vectors of Jamalpur and Rangpur formed an identical angle which represented a strong positive association with each other (Fig. 3B). A similar conclusion was also applicable to the environments of Joydebpur and Ishwardi. However, the correlation between Jamalpur or Rangpur and Borishal was near to null. Nevertheless, small correlation existed among the environments Joydebpur, Ishwardi, Jessore, Dinajpur and Borishal. Thus generalization of different environments becomes difficult or impossible i.e., the environments become independent with an increase of angle between or among different environment vectors.

\section{Mean vs. coefficient of variation (CV\%)}

Mean vs. coefficient of variation $(\mathrm{CV} \%)$ in the polygon view of GGE biplot showing the relationship between genotypic grain yield \& genotypic coefficient of variation across environments (Fig. 4A). Peterson and
Pfeiffer (1989) and Peterson (1992) revealed that identification of suitable zones/locations/environments for varieties/genotypes or a specific variety/genotype will help to know the zone/environment for a group of genotypes or a specific genotype for desirable and stable GY. Genotypic CV across the environments (Francis and Kannenberg, 1978) generally used to categories table genotypes against unstable genotypes. The average genotypic GY was designed against $\mathrm{CV}$ which is directly linked with each genotype (Fig. 4A); for example, a genotype having a low CV and high GY was considered as stable. However, genotypes which gave high CVs did not perform persistently across environments. In the present study, the mean vs. coefficient of variation $(\mathrm{CV}$ $\%$ ) in the polygon view of GGE biplot procedure divided all of the tested genotypes into four groups. The genotypes belong to below right coordinate i.e., genotypes ' $\mathrm{G} 1$ ', 'G2', 'G5', 'G7', 'G11', 'G12' and 'G13' were the most stable genotypes, whereas the genotype 'G10' was moderately stable with high yield.
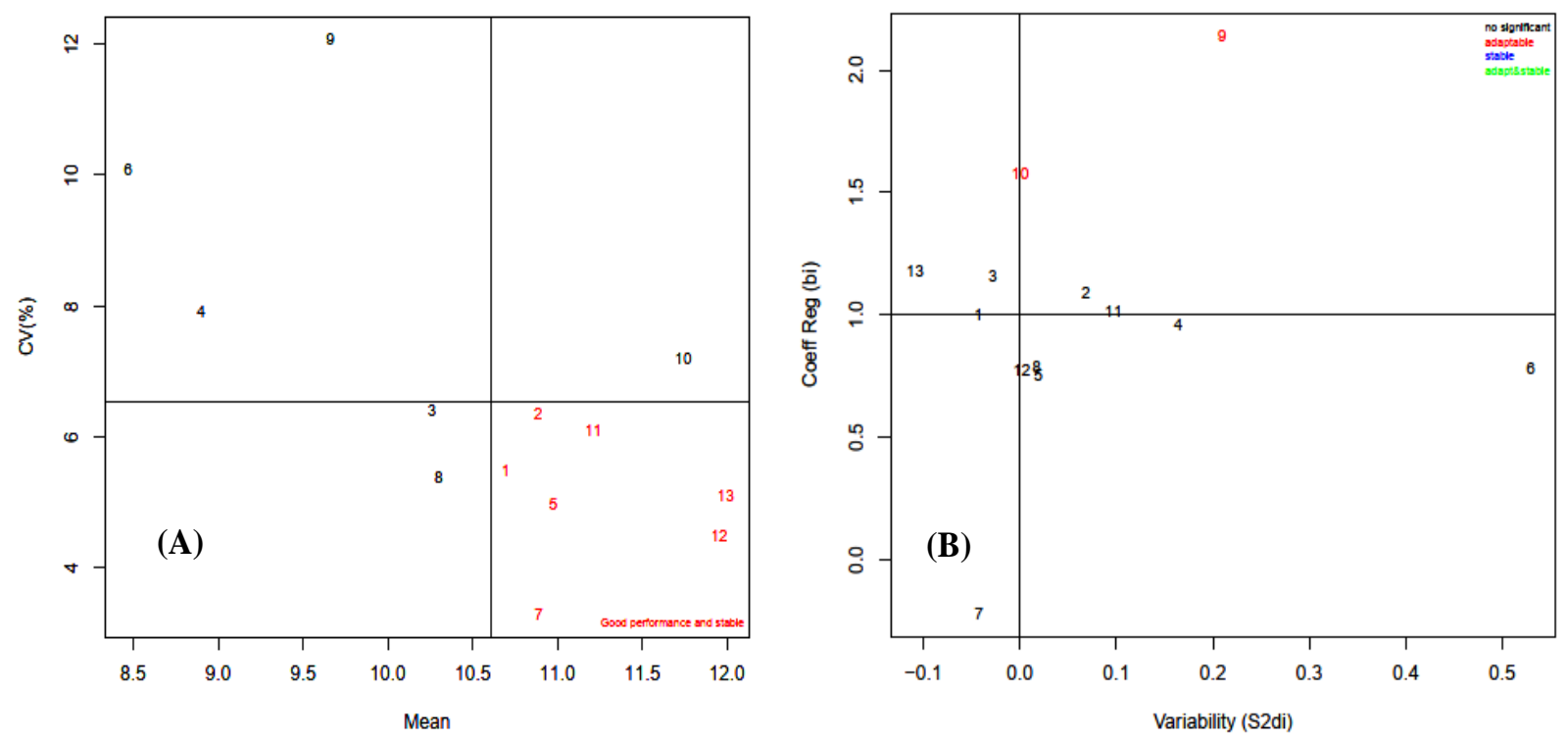

Figure 4. (A) Mean vs. coefficient of variation (CV) \% in polygon view of GGE biplot showing the relationship between genotypic grain yield and genotypic coefficient of variation across environments. (B) The relationship between regression coefficients and deviation from regression across environments in different years

\section{Variability vs. coefficient of regression}

Eberhart and Russell'sregression coefficients (bi) for each genotype were plotted against deviations from regression $\left(\mathrm{s}^{2} \mathrm{di}\right)$ in Fig $4 \mathrm{~B}$. In the present study, the bivalues did not differ significantly from one for four genotypes 'G1', 'G2', 'G4' and 'G11'; while s² di value closed to zero were observed for another four genotypes 'G5', 'G8', 'G10' and 'G12'. Considering this, two genotypes 'G9' and 'G10' were found adaptable, while rest of the genotypes was found no significant.

\section{Stability analysis by AMMI model}

Duarte and Vencovsky (1999) first proposed the AMMI (The Additive Main effects and Multiplicative Interaction) analyses. The AMMI model is the most effective method to find out the genotype(s) which are stable and suitable to cultivate in specific or multiple environments (Zobel et al., 1988). The AMMI biplot analysis is considered the most authoritative interpretive tool for plant breeding program. There are two basic AMMI biplot models: the first one is the AMMI 1 biplot 
model, where the main effects (mean $\mathrm{G}$ and mean $\mathrm{E}$ ) and IPCA1 scores for both $\mathrm{G}$ and $\mathrm{E}$ are plotted against each
other(Fig. 5A); the second biplot is AMMI2, where scores for IPCA1 and IPCA2 are plotted (Fig. 5B).
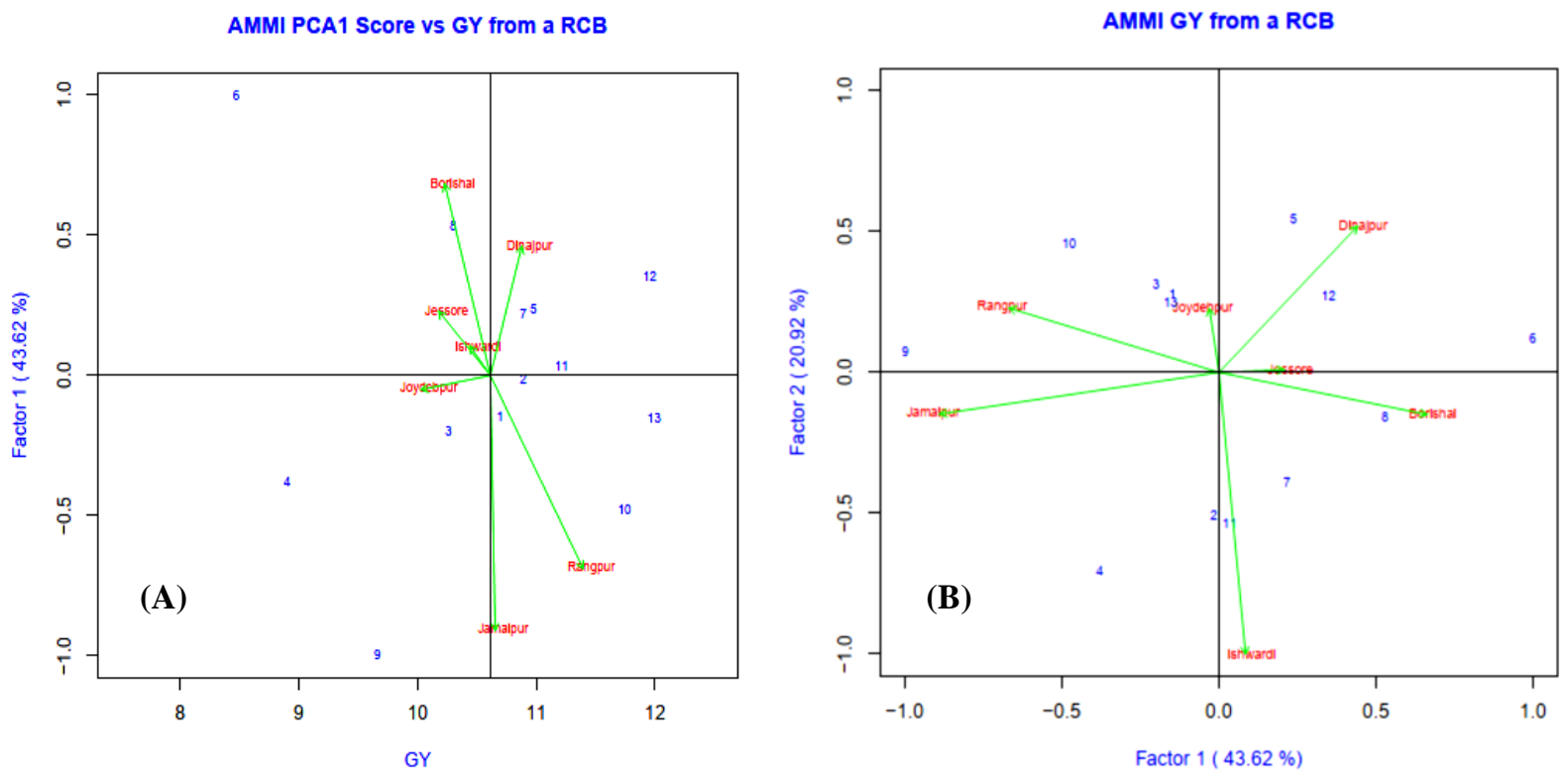

Figure 5. (A) AMMI 1 Biplot for grain yield $\left(\mathrm{t} \mathrm{ha}^{-1}\right)$ of 13 genotypes tested in 7 locations using G \& E scores. (B) AMMI 2 biplot for grain yield $\left(\mathrm{t} \mathrm{ha}^{-1}\right)$ showing the association of IPCA 2 against IPCA 1 scores of 13 genotypes grown in 7 locations.

\section{AMMI 1 biplot display}

In the AMMI 1 biplot, differences in additive or main and interaction effects are represented by displacements along the abscissa and ordinate, respectively. Genotypes belong to the same group have similar adaptation and environments of the same group would influence the genotypes in the same way (Kempton, 1984). Genotype or environment with nearly zero IPCA1 scores is considered as stable genotype and has an insignificant interaction effect. $G$ and $E$ with the identical sign on the PCA axis indicate their positive interaction, while dissimilar sign depicts negative interaction.

High yielder genotypes (G) and favourable environment $(\mathrm{E})$ remain on the right side, while low yielder $G$ and $E$ remain on the left side of $Y$-axis. However, the similar yielder $\mathrm{G}$ and $\mathrm{E}$ are kept on a similar parallel line. In the present study, genotypes ' $\mathrm{G} 5$ ', 'G7', 'G11' and 'G12'had positive IPCA1 score showing high GY together with high main (additive) effects, but the genotype 'G12'was theoverall best. Hence, the genotype 'G12' was well-thought-out the wide range of an ideal genotype. Similarly, positive IPCA1 score of Dinajpur indicated average interaction effects where all the genotypes performed equally although it especially favoured the genotypes 'G5', 'G7', 'G11' and 'G12'. The genotype ' 2 ' was found less influenced by the environments as its IPCA1 score was close to zero (Akter et al., 2014). The genotype ' $G 8$ 'had below average yield and was stable moderately across environments (positive but low IPCA1 score). Moreover, genotypes 'G1', 'G10', 'G13' and environments of Jamalpur and Rangpur had above average yield with negative IPCA1 score indicating that genotypes ' $\mathrm{G} 1$ ' and 'G13'were less and genotype
'G10' was moderately influenced by the environments. However, genotype 'G10' found its favourable environment at Rangpur. The genotypes 'G5', 'G7', 'G11' and ' $\mathrm{G} 12$ ' were hardly influenced with $\mathrm{G} \quad \mathrm{x} \quad \mathrm{E}$ interactionand thus will perform equally to a wide range of environments. As Ishwardi, Jessore and Joydebpurshowed stable yields might be utilized as suitable selection sites for maize improvement. Genotypes 'G6' and 'G9' were least stable, whereas 'G2' and 'G11'were proved as highly stable (Fig. 5A).

\section{AMMI 2 biplot display}

The cross point of two axes is connected with respective environmental scores by sidelines in AMMI 2 biplot (Fig. 5B). The length of sidelines exerts interaction level. The longer sideline means strong interaction, while the shorter sideline indicates weak interaction. Thus, with the short spoke, environments of Joydebpurand Jessore did not exert strong interaction, while the rest of them showed strong interactive forces. However, genotypes close to the origin will have similar GY in all locations, while far apart genotypes will response differentially over environments or in mean yield. Genotypes 'G4', 'G6' and 'G9' were more responsive to environmental interactive forces as they were far away and genotypes ' $\mathrm{G} 1$ ', ' $\mathrm{G} 3$ ' and ' $\mathrm{G} 13$ ' were non-sensitive as they were closer to the origin. Genotypes 'G1', 'G3' and 'G13' were particularly brilliant in Joydebpur, while Dinajpur was particularly suitable for genotypes 'G5' and 'G12'. Likewise, genotypes ' $\mathrm{G} 2$ ', ' $\mathrm{G} 7$ ' and ' $\mathrm{G} 11$ ' were the best performer in Ishwardi and genotype ' $\mathrm{G} 8$ ' acted positively with Borishal. However, genotype 'G10' was the best in Rangpur, while Jamalpur was brilliant for genotype ' $G 9$ '. 


\section{CONCLUSION}

This study indicated that genotypes 'G12', 'G13' and 'G10'were the highest yielder, while genotypes ' $\mathrm{G} 1$ ', 'G2', 'G11' and 'G12' were the most stable across the locations. Five genotypes 'G3', 'G4', 'G6,' 'G8' and 'G9' had the below-average mean yield and genotypes 'G6' and 'G9' were the most unstable. Among the seven environments/locations, Jamalpur, Joydebpur and Dinajpur were the most discriminating and while Ishwardi was the least discriminating, whereas Joydebpur was more representative and Borishal was least representative of other test environments for all genotypes/varieties. In the case of plant and ear height, most of the genotypes showed a lower value than checks. Among the top three high yielding genotypes, genotype ' $\mathrm{G} 10$ ' had the lowest and more stable for both plant and ear height. Therefore, genotype 'G10' has been recommended for release as a commercial variety in Bangladesh with the local name of BARI Hybrid Maize - 16 (BHM-16).

\section{Financial support}

Financial support was provided from the research budget for maize research of Bangladesh Agricultural Research Institute (BARI), Joydebpur, Gazipur.

\section{Conflict of interest}

Authors declared no conflict of interest.

\section{LITERATURE CITED}

Akter, A.,M. Jamil Hassan, M. Umma Kulsum, M.R. Islam and K.Hossain. 2014. AMMI biplot analysis for stability of grain yield in hybrid rice (Oryza sativa L.). J Rice Res. 2(2): 126.

Ali, M.Y., S.R. Waddington, J.Timsina, D.P. Hodson and J.Dixon. 2009. Maize-rice cropping systems in Bangladesh: status and research needs. Journal of Agricultural Science and Technology 3(6): 35-53.

Ariyo, O.J. and M.A. Ayo-Vaughan. 2000. Analysis of genotype $\mathrm{x}$ environment interaction of okra (Abelmoschus esculentus (L) Moench. Journal of Genetics and Breeding 54: 33-40.

Badu-Apraku, B., F.J. Abamu, A. Menkir, M.A.B. Fakorade and K. Obeng-Antwi. 2003. Genotype by environment interactions in the regional early maize variety trials in West and Central Africa. Maydica 48: 93- 104.

Blanche, S.B. and G.O. Myers. 2006. Identifying discriminating locations for cultivar selection in Louisiana. Crop Sci. 46: 946-949.

Choukan, R. 2011. Genotype, environment and genotype $\times$ environment interaction effects on the performance of maize (Zea mays L.) inbred lines. C. B. Journal. 1(2): 97-103.

Comstock, R.E. and R.H. Moll. 1963. Genotype-Environment Interactions. Symposium on Statistical Genetics and Plant Breeding. NASNRC Publication. 982:164-96.

Crossa, J. 1990. Statistical analysis of multilocation trials.Advances in Agronomy 44: 55-85.

Crossa, J., P.N. Fox, W.H. Pfeiffer, S. Rajaram and H.G. Jr. Gauch.1991. AMMI adjustment for statistical analysis of an international wheat yield trial. Theor Appl Genet. 81: 27-37.

Crossa, J., H.G.J. Gauch and R.W. Zobel. 1990. Additive main effects and multiplicative interaction analysis of two international maize cultivar trials. Crop Science 30:493-500.

Das, S., R.C. Misra and M.C. Patnaik. 2009. GxE interaction of mid-late rice genotypes in LR and AMMI model and evaluation of adaptability and yield stability. Environment and Ecology 27(2): 529-535.

Dehghani, H., A. Ebadi and A. Yousefi. 2006. Biplot analysis of genotype by environment interaction for barley yield in Iran. Agron. J. 98: 388-393.

Dimitrios, B., G. Christos, R. Jesus and B. Eva. 2008. Separation of cotton cultivar testing sites based on representativeness and discriminating ability using GGE Biplots. Agron. J. 100: 1230-1236.

Duarte, J.B. and R.Vencovsky.1999.Interação genótipos xambientes: uma introdução a análise AMMI. ESALQ/USP,Ribeirão Preto, SP.

Ebdon, J.S. and H.G. Gauch. 2002. Additive Main Effect and Multiplicative Interaction analysis of national turfgrass performance trials: II. Cultivar recommendations. Crop Science. 42: 497-506.

Eberhart, S.A. and W.A. Russell. 1966. Stability parameters for comparing varieties. Crop Sci. 6: 36-40.

FAOSTAT 2018. FAO statistical database. FAO, Rome, Italy.

Fan, X.M., M.S. Kang, H. Chen, Y. Zhang, J. Tan and C. Xu. 2007. Yield stability of maize hybrids evaluated in multienvironment trials in Yunnan, China. Agron. J. 99: 220-228.

Finlay, K.W. and G.N. Wilkinson 1963. The analysis of adaptation in a plant breeding programme. Australian J. Agric. Sci. 14: 742-54.

Francis, T.R. and L.W. Kannenberg. 1978. Yield stability studies in short-season maize I. A descriptive method for grouping genotypes. Canadian J. Pl. Sci. 58: 1029-1034.

Freeman, G.H. 1985. The analysis and interpretation of interaction. Journal of Applied Statistics. 12(1): 3-10.

Gabriel, K.R. 1971. The biplot graphic display of matrices with application to principal component analysis. Biometrika. 58: 453-467.

Gauch, H.G. 1993. Matmodel version 2.0. AMMI and related analysis for two-way data matrics. Micro computer power, Ithaca, New York, USA.

Gauch, H.G. 2006. Statistical analysis of yield trials byAMMI and GGE. Crop Sci. 46: 1488-1500.

Gauch, H.G. and R.W. Zobel. 1997. Identifying megaenvironments and targeting genotypes. Crop Sci. 37: 311326.

Gerpacio, V.R. and P.L. Pingali. 2007. Tropical and subtropical maize in Asia: Production systems, constraints and research priorities. Mexico, D.F:CIMMYT.

Gulati, A., J. Dixon and J.M. Dixon. 2008. Maize in Asia: changing markets and incentives. Contributors: International Maize and Wheat Improvement Center, International Food Policy Research Institute, International Fund for Agricultural Development. Academic Foundation, pp.489.

Hossain, A., M.Farhad, M.A.H.S. Jahan, M.G. Mahboob, J. Timsina and J.A. Teixeira da Silva. 2018. Biplot yield analysis of heat-tolerant spring wheat genotypes (Triticum aestivum L.) in multiple growing environments. Open Agriculture 3(1): 404-413.

Intergovernmental Panel on Climate Change (IPCC). Climate Change 2007b: Impacts, Adaptation And Vulnerability: An Assessment Report Of The Intergovernmental Panel On Climate Change; Cambridge University Press: Cambridge, UK, 2007.

IPCC. 2001. Climate Change 2001: Impacts, Adaptation and Vulnerability, Summary For Policymakers and Technical Summary of the Working Group II Report, Geneva.

IPCC. 2007. Climate Change 2007a: Impacts, Adaptation and Vulnerability: Contribution of Working Group II to the Fourth Assessment Report of the Intergovernmental Panel on Climate Change. In: Parry ML, Canziani OF, Palutikof JP, 
Van Der Linden PJ, Hanson CE (Eds) Cambridge University Press, Cambridge.

Kaya, Y., M. Akcura and S. Taner. 2006. GGE-biplot analysis of multi-environment yield trials in bread wheat. Turk. J. Agric. Forest. 30: 325-337.

Kempton, R.A. 1984. The use of biplots in interpreting variety by environment interactions. Journal of Agricultural Science 103: 123-135.

Kizilgeci, F., O. Albayrak and M. Yildirim. 2019. Evaluation of thirteen durum wheat (Triticium durum Desf.) genotypes suitable for multiple environments using GGE biplot analysis. Fresenius Environmental Bulletin, 28(9): 68736882.

Knight, R. 1970. The measurement and interpretation of genotype-environment interactions. Euphytica 19(2): 225235.

Langridge, J. and B. Griffing. 1959. A study of high-temperature lesions in Arabidopsis thaliana. Australian J. Biol. Sci. 12: $117-35$.

Letta, T., M.G. D'Egidio and M. Abinasa. 2008.Analysis of multi-environment yield trials in durum wheat based on GGE-biplot electronic resource. J.Food, Agric. Environ. 6(2): 217-221.

Lin, C.S., M.R. Binns and L.P. Lefkovitch. 1986. Stability analysis: Where do we stand? Crop Sci. 26: 894-900.

McLaren, C.G. and C. Chaudhary. 1994. Use of additive main effects and multiplicative interaction models to analyse multilocation rice variety trials. Paper presented at the FCSSP Conference, Puerton Princesa, Palawan, Philippines.

Mohammadi, R., A. Amri and Y. Ansari. 2009. BiplotAnalysis of rain-fed barley multi-environment trials in Iran. Agron. J. 101: 789-796.

Mohammadi, R., M. Armion, E. Zadhasan, M.M. Ahmadi and D. Sadeghzadeh Ahari. 2012. Genotype $\times$ environment interaction for grain yield of rainfed durum wheat using the GGE biplot model. Seed and plant Improv. J. 28-1(3): 503518.

Mohammadi, R., R. Haghparast, A. Amri and S. Ceccarelli. 2010. Yield stability of rainfed durum wheat and GGE biplot analysis of multi-environment trials. Crop Past. Sci. 61: 92101.

Moreno-Gonzalez, J., J. Crossa and P. L. Cornelius. 2004. Genotype $\times$ environment interaction in multi-environment trials using shrinkage factors for AMMI models. Euphytica. 137: 119-127.

Nasreen, M. 2008. Sustainable development and impacts of climate change: A Gender Perspective. ITN, BUET.

Nassir, A.L. 2013. Genotype x Environment analysis of some yield components of upland rice (Oryza sativa L.) under two ecologies in Nigeria. InternationalJournal of Plant Breeding and Genetics. 7: 105-114.

Ozaki, M.2016. Disaster risk financing in Bangladesh, ADB SOUTH ASIA Working Paper Series, no. 46.

Pacheco, R.M., J.B. Duarte, M.D.S. Assunção, J. Nunes Júnior and A.A.P Chaves. 2003. Zoneamento e adaptação produtiva de genótiposde soja de ciclo médio de maturação para Goiás. PesquisaAgropecuária Tropical 33: 23-27.

Perkins, J.M. and J.L. Jinks. 1968. Environmental and genotypeenvironmental components of variability. III. Multiple lines and crosses. Heredity 23: 339-356.

Peterson, C.J. and W.H. Pfeiffer, 1989. International Winter Wheat Evaluation: Relationships among Test Sites Based on Cultivar Performance. Crop Sci. 29: 276-282.

Peterson, C.J. 1992. Similarities of test sites based on cultivar performance in the hard red winter wheat region. Crop Sci. 32: 907-912.
Plaisted, R.L. and L.C. Peterson. 1959. A technique for evaluating the ability of selections to yield consistently in different locations or season. American Potato J. 36: 381385.

Plaisted, R.L. 1960. A shorter method for evaluating the ability of selections to yield consistently over locations. American Potato J. 37: $166-172$.

Prasad, K.V. and R.L.Singh. 1990. Stability analysis of yield and yield components and construction of selection indices of direct-seeded rice in frost season.Annual Review conference Proceeding. 20-23 October 1992. National Agric.Res. Inst. Caribbean Agricultural Research and Development Institute, Guyana, pp. 63-71.

Prasanna, B.M., A. Das and K.K. Kaimenyi. 2018. Book of Extended

Summaries, 13th Asian Maize Conference and Expert Consultation on Maize for Food, Feed, Nutrition and Environmental Security. Ludhiana, India, October $8-10$, 2018. CIMMYT, Mexico D.F.

R Core Team. 2013. R: A language and environment for statistical computing. $\mathrm{R}$ Foundation for Statistical Computing, Vienna, Austria, 2013. ISBN 3-900051-07-0, URL <http://www.R-project.org/>, (Last accessed on 11 March, 2019)

Samonte, S.O.P.B., L.T. Wilson, A.M. Mc Clung andJ.C. Medley. 2005. Targeting cultivars onto ricegrowing environments using AMMI and SREG GGEbiplot analysis. Crop Sci. 45: 2414-2424.

Rahman, S., Md. Touhiduzzaman and I. Hasan. 2017. Coastal livelihood vulnerability to climate change: a case study of char montaz in Patuakhali District of Bangladesh. American Journal of Modern Energy 3(4): 58-64.

Shinde, G.C., M.T. Bhingarde and S.S. Mehetre. 2002. AMMI analysis for stability of grain yield of pearl millet (Pennisetum typhoides L.) hybrids. InternationalJournal of Genetics 62: 215-217.

Shiferaw, B., B. Prasanna, J. Hellin and M. Banziger. 2011. Crops that feed the world. 6. Past successes and future challenges to the role played by maize in global food security. Food Security 3: 307-327.

Shiri, M. 2013. Grain yield stability analysis of maize (Zea mays L.) hybrids in different drought stress conditions using GGE biplot analysis. Crop Breeding Journal 3(2):107-112.

Shukla, G.K. 1972. Some statistical aspects of partitioning genotype environment components of variability. Heredity 29: 237-245.

Tarakanovas T. and V. Rugas. 2006. Additive main effect and multiplicativeinteraction analysis of grain yield of wheat varieties in Lithuania. Agronomy Research 4: 91-98.

Taye. G., T. Getachew and G. Bejiga. 2000. AMMI adjustment for yield estimate and classifications of genotypes and environments in field pea (Pisum sativum L.). Journal of Genetics and Breeding 54: 183-191.

Timsina, J., M.L. Jat and K. Majumdar. 2010. Rice-maize systems of South Asia: current status, future prospects and research priorities for nutrient management. Plant and Soil. 335(1-2): 65-82.

Timsina, J., J. Wolf, N. Guilpart, L.G.J. Van Bussel, P. Grassini, J. Van Wart, A. Hossain, H. Rashid, S. Islam and M.K. Van Ittersum. 2018. Can Bangladesh produce enough cereals to meet future demand?. Agricultural systems 163: 36-44.

Wricke, G. 1962. Uber eine Methode zur Erfassung der okologischen Streubreite in Feldversuchen Z.Pflanzenzuecht, 47: 92-96. 
Yan, W. andL.A.Hunt. 2001. Interpretation of genotype $\mathrm{x}$ environment interaction for winter wheat yield in Ontario. Crop Science 41: 19-25.

Yan, W. and I. Rajcan. 2002. Biplot analysis of test sites and trait relations of soybean in Ontario. Crop Sci. 42: 11-20.

Yan, W. and L. A. Hunt. 2002. Biplot analysis of diallel data. Crop Sci. 42: 21-30.

Yan, W. and M. S. Kang. 2003. GGE biplot analysis: A graphical tool for breeders, geneticists, and agronomists. CRC Press, Boca Raton, FL, USA.

Yan, W. and N. A. Tinker. 2006. Biplot analysis of multienvironment trial data: Principles and applications. Can. J. Plant Sci. 86: 623-645.
Yan, W., L.A. Hunt, Q. Sheng and Z. Szlavnics. 2000. Cultivar evaluation and mega-environment investigations based on the GGE biplot. Crop Sci. 40: 597-605.

Yan, W., P.L. Cornelius, J. Crossa and L.A. Hunt. 2001. Two types of GGE biplots for analyzing multi-environment trial data. Crop Sci. 41: 656-663.

Yau, S.K. 1995. Regression and AMMI analyses of genotype $\mathrm{x}$ environment interactions: An empirical comparison. Agronomy Journal 87: 121-126.

Zobel, R.W., M.J. Wright and H.G. Gauch. 1988. Statistical analysis of a yield trial. Agronomy Journal. 80: 388-393. 